\title{
Organizational Effectiveness in Bosnia and Herzegovina: A Competing Values Approach
}

\author{
Matea Zlatković \\ University of Banja Luka, Faculty of Economics, Banja Luka, Bosnia and Herzegovina
}

\begin{abstract}
Many different measures of organizational effectiveness have been proposed and one, widely used, based on Quinn's competing value framework, was applied in various national contexts. The competing values framework describes organizational effectiveness as paradoxical and contradictory by nature and in terms of seemingly mutually exclusive value dimensions, such as flexibility versus control and internal focus versus external focus. The competing values framework was broadly employed to examine various organizational phenomena, such as leadership, organizational commitment, organizational culture and decision making, and thus providing universal metric for trans-organizational analyses for different levels. This study presents the research results of 150 managers' perceptions of effectiveness of Bosnia and Herzegovina's organizations according to competing values approach. Multidimensional scaling was employed. It provides qualified support to structure of the competing values framework and shows that seemingly opposite organizational effectiveness models really coexist and can be effectively managed to accomplish and fulfil planned organizational goals.
\end{abstract}

Keywords

Organizational effectiveness, competing values framework, value dimensions, multidimensional scaling analysis.

\section{Introduction}

Since the early days of industrialization, the organizational effectiveness has been central subject in many organizational researches. The importance of the organizational effectiveness can be reflected in the fact that "organizational effectiveness is the ultimate question in any form of organizational analysis." (Hall, 1980, p. 536). At first, following machine analogy of organizations, the organizational effectiveness referred substantially to efficiency. However, the changes of the organizational concepts have changed, understanding efficiency as effectiveness.

In the recent period, broadly organizational effectiveness concepts and development of the variety of organizational effectiveness models have been revealed. Many definitions of the term organizational effectiveness have been characterized by tautologies, advice and contradictories. Complexity in understanding organizational effectiveness varies from simple definition that "an activity is considered to be effective if achieves specific objectively defined goal" (Barnard, 1938, p. 20) to understanding that effectiveness is not only an abstract term in pure science, but rather a precise focus and concept in the applied science. The level of complexity of the organizational effectiveness research is higher due to including complexity issues such as dynamic nature of the organizational goals so organizational analyses become comparative by nature not scientifically based. Some authors believe that organizational effectiveness is a value concept and that there is an unlimited number of organizational effectiveness models because of the unlimited number of values. Complexity of the organizational effec- 
tiveness is present due to the fact that organizational effectiveness concept is not unique. Organizational effectiveness is regarded as ,society construct and abstract term placed in mind of the organizational theorists and researchers" (Quinn \& Rohrbaugh, 1983, p. 374). Many issues about organizational effectiveness assessment include the fact that organizational effectiveness represents something that stakeholders believe it represents. There are many different approaches to defining and measuring organizational effectiveness. The competing values approach as comprehensive and dynamic approach is discussed in this study.

However, Quinn's competing values framework for organizational effectiveness was not empirically tested in Bosnia and Herzegovina context. Until date, basic assumptions of the competing values framework used to describe organizational effectiveness have not been fully validated. Specially, there has been no published research examining validity and reliability of the competing values framework for measuring organizational effectiveness when used in case of Bosnia and Herzegovina's organizations. This study aims to fill this important gap in the literature by presenting the results of a survey of the 150 managers of the Bosnia and Herzegovina's organizations who participated in survey on organizational effectiveness observed through value dimensions represented in competing values approach. This study is exploratory by nature and it proceeds by way of following hypothesis: The inter correlations of the organizational effectiveness items can be represented in a two-dimensional multidimensional scaling representation that strictly satisfies the competing values framework in case of Bosnia and Herzegovina.

The purpose of the study was to employ competing values framework instrument in the different economic context such as Bosnia and Herzegovina and to establish the psychometric characteristics of the instrument in this national context. Competing values instrument was used to evaluate organizational effectiveness. Reliability and correlation analysis were performed in order to establish internal consistency of different models of organizational effectiveness and theirs inter correlation. Finally, multidimensional scaling analysis is employed to test the consistency of empirical results and theory of organizational effectiveness in observed national context. Results showed that competing values framework instrument for measuring organizational effectiveness seems to be a useful measure that gave valuable information about Bosnia and Herzegovina's organizational profiles and its effectiveness.

In the first part of the study, literature review of the competing values approach application is presented, which suggests that the competing values approach is a valuable way of operationalization of organizational effectiveness in various developed economies. Next, the methodology used in this study is presented, followed by the details of the data analysis and obtained results. The results suggest that the competing values approach to organizational effectiveness is both valid and reliable in the Bosnia and Herzegovina context. In addition, some implications for the managers of the Bosnia and Herzegovina's organizations are discussed.

\section{Literature review}

Organizational effectiveness is one of the bases of management and organization theory and practice. It represents the very centre of all organization theory and is becoming the main theme in organizational sustainability (Young \& Tilley, 2006). The increasing need to assess the effectiveness is present not only at individual but also on organizational level. Organization can be perceived as organic system which develops certain types of systems, processes and conducts, with aim to fulfil the objectives. If it aims to be perceived as effective, organization has to coordinate individuals, business strategies and systems with competence development (Andreadis, 2009).

\subsection{Organizational effectiveness as phenomenon}

Some authors believe that organizational effectiveness represents the useful measure of the organizational goals and missions (Jamrog \& Overholt, 2004). Modern business environment has the high level of dynamism and uncertainty. The uncertainty dimension reflects to ambiguous and complex environmental conditions that influence business decisions. The dynamism dimension of the environment reflects to the intensity and frequency of changes in external environment. The environmental changes can put certain amount of pressure on the organizations and their capability to adapt their business strategies to satisfy changed environmental conditions (Morris et. al., 2005; Schneider \& Spieth, 2013). Individuals and organizations have to simultaneously understand and adapt to changing environmental conditions. Many organizations fail because of their inability 
to change and adapt organizational processes and systems to the environmental conditions. Organizational processes and systems have to function in a way that they encourages individuals to make themselves evaluations and judgments in adapting to changing environments (Tushman \& O'Reilly, 1996). Employees have the central role in organizational effectiveness. Including employees in organizational process can provide productivity and effectiveness through enhancement of the solving problems and making right decisions (Sundaray, 2011). Organizational effectiveness can be perceived as multidimensional and multivariate construct that explains various organizational domains of activities (Cameron \& Freeman, 1991). The emphasized dimension of goal orientation and process emerges from measuring organizational effectiveness (Lemieux-Charles et. al., 2003). Organizational effectiveness can be negatively related to goal ambiguity (Chun \& Rainy, 2005) and those organizations that had precise objectives had higher performance. Also, if employees perceive strategic planning as important, then they have clear understanding in their work duties in organization. Further, leaders have important role in achieving organizational effectiveness. Leaders have to be more adaptable and emphatic toward employees in order for an organization to be effective. Consistency with mission and vision is important for an organization to be effective and to adapt and respond to all types of pressure coming from business environment (Fey \& Denison, 2003).

Some studies investigated the relationship between organizational effectiveness and culture (Cameron \& Freeman, 1991). It is concluded that culture values are the significant part of the external business environment that have influence on the organizational performance. In order to achieve organizational effectiveness as a whole, productivity as a part of organizational effectiveness especially related to employees has to be investigated. Organizational capability to convert knowledge and technologies aligned with environment conditions and market demands enable organizational effectiveness. Furthermore, organizational effectiveness depends on organizational ability to overcome all obstacles and adapt to changing environment (Chermack et. al., 2010).

The important characteristics of organizational effectiveness are efficiency and adaptation. Efficiency of internal processes and adaptation and responsiveness to external conditions and opportunities jointly influence organizational success
(Yukl \& Lepsinger, 2004). Efficiency presents the extent to which the organization is willing to minimize its costs in order to provide basic functioning. Also, efficiency is influenced by the amount of which work processes are conducted without delays and errors. The main determinants of efficiency are percentage of revenue which presents costs, costs compared to those for competing business and productivity of employees compared to labour costs. Many studies confirm that reduction of these costs and elimination or minimizing of errors, accidents and delays lead to improvement of organizational performance (Ebben \& Johnson, 2005; Key et. al., 2005). Reducing labour costs, outsourcings work activities, minimizing costs of energy and materials and excess inventory, and redesigning organizational processes represent ways of improving organizational efficiency. Efficiency improving is much easier in stable rather than in dynamic business environment where conditions are constantly changing. There are many difficulties facing organizational efficiency accomplishment when there are constraints on the minimizing or reduction of cost such as safety regulations and quality standards that have to be fulfilled, short life cycles of certain materials or energy, obligatory rules for minimum salaries and employment guaranties, etc. When a firm has a business strategy that comprises of supplying products and services at lower prices compared to competition, efficiency becomes a very important factor for organizational success. Importance of efficiency is emphasized for organizations that have few large clients who demand reduction of costs but it becomes less important when organizations can continue to have high costs due to increasing prices of products and services.

Organizational effectiveness also depends on the capability of an organization to adapt to changes in the external environment. Organizational capabilities to change aligned with environment changes imply increases in market share and sales and building and maintaining loyalty and satisfaction of its clients. In order to successfully adapt to environment dynamics, organizations have to have precise, accurate and forehand information about changes and opportunities in business environment. Adaptation capability is pronounced and developed through organizational learning according to how an organization is prepared to effectively respond to changes and opportunities that the organization faces. Organization adaptation often requires innovative changes 
facilitated by creativity, flexibility and quality of product (Baer \& Frese, 2003). There is lower possibility that organization adaptation will be successful when the management is unwilling to change business strategies which were previously confirmed to be successful but are not any more appropriate in a changed business environment. Sometimes the management strongly believes that there is nothing else that can be learned from competitors which interfere with successful organization adaptation aligned with changing business environment (Finklestein, 2003). Without detail risk analysis and capabilities analysis there is a danger that some responses to threats and business opportunities can lead to unsuccessful organizational performance if they are based only on management instincts (Finklestein, 2003). In today's economy based on knowledge, where uniqueness is the essential competitive condition for sustainable performance and above-average success, innovation changes and adaptation is a very important key for satisfaction of continuously changing market demands. When competition is low, organizations are not under enormous pressure to adapt and quickly respond to customer wants and needs by improving customer service and product quality.

Internationalization of business activities, globalization processes and informationcommunication technologies lead to increasing the need to establish and further develop organizational capabilities to adapt and quickly change align with environmental changes and threats and to incorporate in everyday organizational functioning a systematic monitoring mechanism of external environment and detecting potential dangerous and opportunities that could affect business activities.

\subsection{The competing values framework}

Quinn and Rohrbaugh determined the competing values framework while exploring potential relations among the notions of organizational effectiveness (Quinn \& Rohrbaugh, 1983). The respondents were asked to assess existence of similarities among various indicators of organizational effectiveness and then performed data analysis by multidimensional scaling technique. An organization can be characterized as a dynamic and contradictory system with its manager obligated to accomplish competing objectives. One can identify four organizational effectiveness models that reflect the presence, in a certain amount, of the dimensions of competitive values. The two primary dimensions reflected preference toward either control or flexibility and internal versus external focus. By crossing these two dimensions at their centres, four distinctive organizational effectiveness models emerged. Each of these four models has their own particular goals and objectives or special processes for objective accomplishments. Also, beside these two dimensions there exist third dimension means-ends. Every organizational effectiveness model has these values and some of them appear to be mutually exclusive. Competing values framework (CVF) of organizational effectiveness is depicted in Figure 1.

Organizational effectiveness models in CVF vary along two dimensions in terms of the extent to which they favour flexibility over control and internal over external focus (Quinn, 1988). The human relations model of organizational effectiveness (HR) characterizes favour of flexibility and internal organizational focus. It emphasizes employee commitment and highly values human resources, training, cohesion and employee morale. The open systems model of organizational effectiveness (OS) characterizes favour of flexibility and external organizational focus. It is focused on capabilities to expand and adapt to external environment conditions and highly emphasizes growth, readiness, acquisition of resources, external support and adaptability. The internal process model of organizational effectiveness (IP) is oriented to control and has internal organizational focus. It favours consolidation and continuity and emphasizes information and communication management and stability. The rational goal model of organizational effectiveness (RG) has external organizational focus and orientation toward control. Its objective is to maximize output and achieve efficiency, productivity, planning and defining goals. 


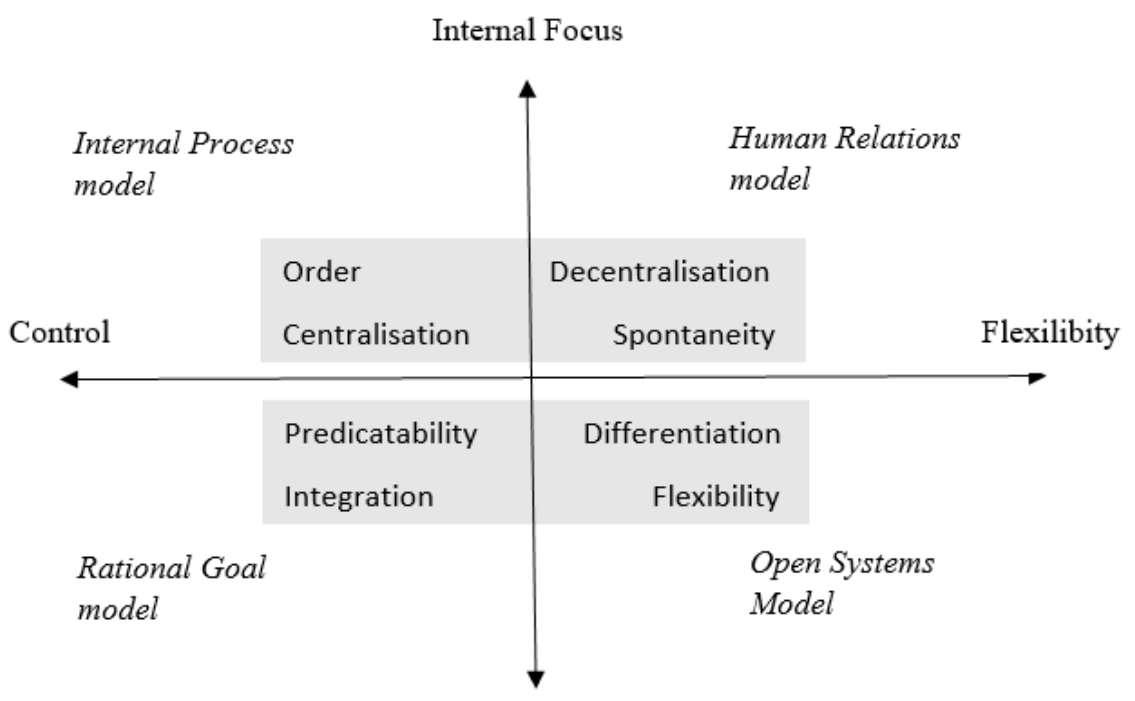

Figure 1 Taxonomy of the organizational effectiveness defined by competing values framework Source: Adapted from Quinn, 1988

HR organizational effectiveness model does not share any common values with RG organizational effectiveness model. They are polarly opposite to each other and diagonally located in spatial two-dimensional visual representation as shown in Figure 1. Similarly, IP organizational effectiveness model and OS organizational effectiveness model are polarly opposite to each other. Also, adjacent organizational effectiveness models are significant to be considered. Value dimension flexibility is shared among HR and OS organizational effectiveness models. On the other hand, control orientation is common for RG and IP organizational effectiveness models. OS and RG organizational effectiveness models have external focus as common value dimension, while IP and HR organizational effectiveness model share internal focus as common value dimension.

The competing values framework named organizational effectiveness construct as competing values construct because of its paradoxical, conflicting and contradictory nature (Quinn, 1988). Although some organizational effectiveness models are located opposite to each other in twodimensional visual representation, many organizations can be simultaneously adaptable and flexible and also controlled. At the same time, organizations can have emphasized on validation of human resources and accomplishment of efficiency and productivity
(Quinn, 1988). Organizations may want to acquire resources, growth and have external support, but also to establish formal communication and close information management. Simultaneously, organization can emphasize human resources.

This competing values organizational effectiveness construct does not imply that opposite organizational effectiveness models cannot exist at the same time in one organization. These models do not exclude the simultaneous existence of each other in organization. They are perceived to be mutually exclusive because they are based on assumptions according to which they can be regarded as opposite models. Quinn recommends the establishment of balance between all four organizational effectiveness models presented in competing values framework even though these models emphasize contradictory and conflicting goals and objectives. It is suggested that caution is necessary because organizational effectiveness models at the extremes are more probably to be dysfunctional.

\subsection{Universal nature of the competing values framework}

The competing values framework was partially developed to bring clarity in effectiveness. According to CVF, organization is seen as paradoxical and this approach suggests that achieving high performance requires an organization and its topmanagers to simultaneously perform contradictory 
and paradoxical roles and capabilities. The CVF of organizational effectiveness consists of three fundamental paradoxes known in the literature: flexibility versus stability orientation; internal versus external organizational focus; and means versus ends (Quinn \& Rohrbaugh, 1983; Quinn, 1988; Hart \& Quinn, 1993).

At first, the competing values framework is used to indicate taxonomy of organizational effectiveness. There are studies testing the validity of the Quinn's original competing value framework which offer some support for the proposed model (Buenger et. al., 1996; Kalliath et. al., 1999). In further research, this framework is used to explain various concepts such as organizational transitions, organizational decision making, organization communications, and CEO leadership. Furthermore, it has been applied to show how certain values dimensions of organization can be affected by its belonging to different types of industry and differences between public and private ownership. Application of the competing values framework allowed to examine organizational ethics, and more broadly in explaining organizational culture, where existence of varieties was due to differences in organizational performance and quality of work life perception.

Universal application of the competing values framework is confirmed by many obtained empirical results from other research that supported the two-dimensional model indirectly. For instance, there is a study that has used four quadrant structure of the competing values framework to examine CEO leadership in the public sector. Several organizational phenomena were described using competing values framework such as: organizational commitment, human resource management, military leadership, gender in management, and leadership of orchestras.

\section{Research methodology}

Competing values instrument (CVI) was used to evaluate organizational effectiveness. The main purpose of the CVI is to measure perception of the respondents of their organizational conditions and environment. In this way, certain organizational profile consistent with the competing values framework is generated. CVI contains 16 statements among each of them represent certain values that are characteristic for one of the four models proposed by competing values framework. These models are as follows:
- HR - hrl (participation and open discussion), hr2 (employee concerns and ideas), hr3 (moral and cohesion) and hr4 (commitment and loyalty);

- OS - os1 (innovation and change), os2 (creative problem solving), os3 (decentralization) and os4 (new ideas)

- RG - rg1 (outcome excellence and quality), rg2 (getting the job done), rg3 (goal achievement) and rg4 (doing one's best) and

- IP - ip1 (predictable outcomes), ip2 (stability and continuity), ip3 (order) and ip4 (dependability and reliability).

Respondents had to indicate to which extent they agree with level of application of each statement in their organization, on a seven-point Likert scale, from 1 meaning "very strongly disagree" to 7 meaning "very strongly agree".

The CVI was administered by personal paperand-pencil and online survey questionnaire designed to investigate presence of certain models of organizational effectiveness and validate the competing values framework in specific organizational settings in transition countries. The sample comprised 150 respondents to the survey who were executives working as middle and senior managers or owners of the business. At the time of the survey, the majority ( 88 per cent) were working in micro, small and medium organizations ( $<250$ employees) and working in the service sector (62 per cent). There were no systematic variations in the sample demographic and organizational variables of practical significance.

The obtained data were analyzed using the Statistical Package for the Social Sciences (SPSS), release 7.5.1. Nonmetric multidimensional scaling (MDS) was employed. This analysis operates on the dissimilarities among data points. MDS provides graphic representations of the variables according to these dissimilarities in a certain number of dimensions as data suggests. As a MDS product it is spatial representation of the distances among data. MDS has been proven as effective protocol for empirically determining taxonomies through identification and modelling the structure and dimensions of a set of data. Many researchers apply this tool for studies involving the competing values framework. 


\section{Results and Discussion}

If the obtained MDS results are compatible with those expected by competing values framework, as shown in Figure 1, then human relations model's items (hr1, hr2, hr3 and hr4) should appear together in one quadrant while rational goal model's items (rg1, rg2, rg3 and rg4) should appear in quadrant that is diagonally opposite because these models do not share same values. The same situation applies to internal process model and open systems model. Internal process model's items (ip1, ip2, ip3 and ip4) should appear together in one quadrant while open systems model's items (os1, os2, os3 and os4) should appear together in the quadrant adjacent to the rational goal model and diagonally opposite the quadrant that contains open systems model's items (os1, os2, os 3 and os4).

Results of the multidimensional scaling for the 16 statements that constitute instrument for measuring competing value framework in Bosnia and Herzegovina's context are shown in Figure 2.

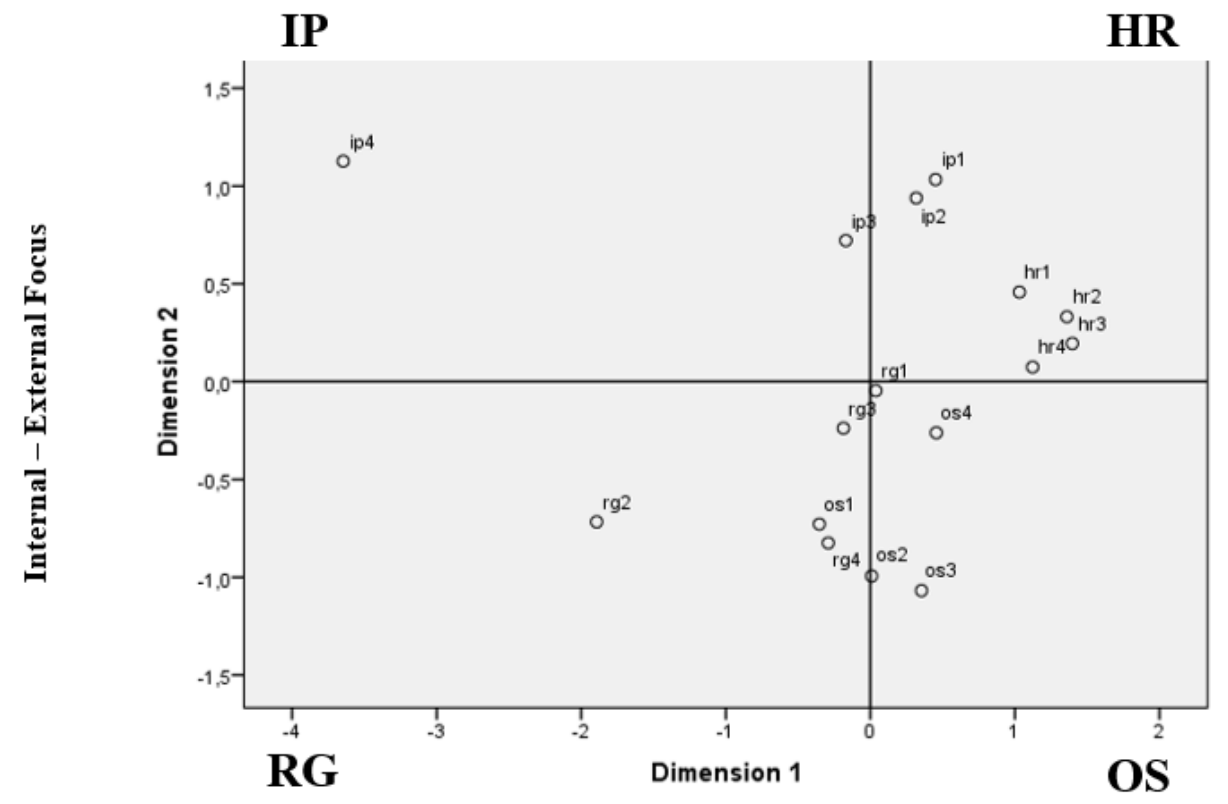

Control - Flexiblity Orientation

Figure 2 Multidimensional scaling - derived stimulus configuration for competing values scale (Euclidean distance model) Source: Author

It can be concluded that these statements of the organizational effectiveness models generally conform to the competing values framework. The majority of them appear in the expected quadrants. The position of a certain number of statements is not in accordance with the proposed positions in expected quadrants but still they have certain values characteristic of those from expected quadrants. The appearance of the items ip1 and ip2 in human relation model's quadrant, item rg1 in open systems model's quadrant and item os1 in rational goal model's quadrant represent a departure from the competing values framework. Nevertheless, their new positions are still consistent with the theory because human relation model and internal process model quadrants still share emphasis on internal focus, while the human relations model and open system model quadrants share emphasis on flexibility. The rational goal model and open systems model quadrants share emphasis on an external focus. Items ip1 and ip2 are in the human relations model's quadrant but they are still very much at the expected internal end. Item os 1 is in rational goal model's quadrant but it is still toward expected external end. Item rg1 does not have pronounced any values dimension.

In Table 1, descriptive statistics are shown for all four organizational effectiveness models from competing values framework and for overall scale of organizational effectiveness. Reliability of subscales and overall scale was established. The coef- 
ficient Cronbach's alpha for testing reliability of scales is used. Its value for the competing values scale as a whole was 0.916 . The Cronbach's alpha reliabilities for each of the subscale measuring four organizational effectiveness models indicate that reliabilities are quite acceptable, values between 0.788 and 0.921 , and represent "satisfactory to good" reliability levels (Hair et. al., 2017b, p. 112). The results of the MDS and reliability analysis indicate the measurement instrument of the competing values framework has construct validity and it can be seen as reliable measure of the competing values framework.

Table 1 Reliability, mean scores, standard deviations and correlations for the organizational effectiveness model in competing values framework

\begin{tabular}{|l|r|r|r|r|r|r|c|}
\hline & \multicolumn{1}{c|}{$\begin{array}{c}\text { Cronbach's } \\
\text { alpha }\end{array}$} & $\begin{array}{c}\text { Mean } \\
\text { score }\end{array}$ & \multicolumn{1}{c|}{ SD } & $\begin{array}{c}\text { Human } \\
\text { relations }\end{array}$ & $\begin{array}{c}\text { Internal } \\
\text { process }\end{array}$ & Rational goal & $\begin{array}{c}\text { Open } \\
\text { systems }\end{array}$ \\
\hline Human relations &, 921 & 5,7783 & 1,17850 & & & & \\
\hline Internal process &, 788 & 5,3733 & 1,04582 &, $400^{* *}$ & & & \\
\hline Rational goal &, 818 & 5,2383 &, 98280 &, $409^{* *}$ &, $481^{* *}$ & & \\
\hline Open systems &, 878 & 5,2850 & 1,18507 &, $707^{* *}$ &, $470^{* *}$ &, $578^{* *}$ & \\
\hline Total scale score &, 916 & 5,4188 &, 87535 &, $810^{* *}$ &, $727^{* *}$ &, $758^{* *}$ &, $879^{* *}$ \\
\hline
\end{tabular}

Note: All significant at $p<0.01$ (two-tailed)

Source: Author

Correlations between each of the organizational effectiveness models and with the total scale score of the competing values framework are all positive as shown in Table 1. Also, it can be seen that mainly organizational effectiveness models that share common values have higher correlations in comparison to organizational effectiveness models which are in the quadrant diagonally opposite. However, obtained results can be considered counterintuitive having in mind that they are measures of the competing values. As suggested by Quinn (1988), all four organizational effectiveness models coexist in every organization, with certain values more pronounced than others, and so the subscales of each organizational effectiveness model measure the extent to which every approach to effectiveness is present in or- ganization. Competing values instrument measures the perception of the managers of the overall intensity of the organizational effectiveness. Obtained results cannot be considered inconsistent with the theory or with results of MDS.

The horizontal axis supports a control versus flexibility interpretation. Item $\mathrm{hr} 3$ demonstrates the highest positive weight (1.3978) on the dimension, while item ip4 produces the highest negative weight (-3.6467), and visually they are most distal. The vertical axis supports an interpretation as internal versus external focus. The defining values for item os3 (weight -1.068) represent a focus on flexibility and external adaptation versus values for item ip4 (weight 1.1264), which focus on control and internal integration.

Table 2 Multidimensional Scaling Stimulus Coordinates

\begin{tabular}{|r|l|r|r|}
\hline \multicolumn{3}{|c|}{ Dimension } \\
\hline Stimulus & Plot symbol & 1 (Control-Flexibility orientation) & 2 (Internal-External focus) \\
\hline 1 & hr1 & 1.0314 & 0.4574 \\
\hline 2 & hr2 & 1.3598 & 0.3313 \\
\hline 3 & hr3 & 1.3978 & 0.1947 \\
\hline 4 & hr4 & 1.1224 & 0.0744 \\
\hline 5 & ip1 & 0.4514 & 1.033 \\
\hline 6 & ip2 & 0.3174 & 0.9385 \\
\hline 7 & ip3 & -0.1694 & 0.7216 \\
\hline 8 & ip4 & -3.6467 & 1.1264 \\
\hline
\end{tabular}




\begin{tabular}{r|l|l|r|r|}
9 & $\operatorname{rg} 1$ & 0.0381 & -0.0463 \\
\hline 10 & $\operatorname{rg} 2$ & -1.8931 & -0.7169 \\
\hline 11 & $\operatorname{rg} 3$ & -0.1862 & -0.2381 \\
\hline 12 & $\operatorname{rg} 4$ & -0.2905 & -0.8246 \\
\hline 13 & os1 & -0.3524 & -0.7282 \\
\hline 14 & os2 & 0.0093 & -0.9937 \\
\hline 15 & os3 & 0.354 & -1.068 \\
\hline 16 & os4 & 0.4567 & -0.2616 \\
\hline
\end{tabular}

Source: Author

The MDS bidimensional model presents not so good but acceptable goodness-of-fit. Stress value was equal to 0.18 which is considered fair fit (Kruskal, 1964). R-squared represents the squared correlation coefficient between the estimated distances and the observed distances between data points and is analogous to the R-squared in multiple regression. An R-square of 0.6 is considered the minimum acceptable level (Hair et. al, 1998). An R-square of 0.8 is considered good for metric scaling and 0.9 is considered good for non-metric scaling. MDS results have R-squared correlation .90686 which is acceptable.

\section{Conclusion}

The aim of this study is to examine the psychometric properties of the instrument of the competing values framework for measuring organizational effectiveness (Quinn, 1988) in the Bosnia and Herzegovina organizational context. The findings show that the examined instrument is both a valid and reliable measure. As a consequence, the research results suggest that competing values framework is valuable as a approach to operationalize organizational effectiveness, when the competing values framework is applied in a various national contexts. According to the author's knowledge, this study represents the first attempt to validate competing values framework used for measuring organizational effectiveness in Bosnia and Herzegovina as a representation of transition, factor-driven economy with lower level of economic development. Even though differences in level of economic development exist, results of MDS suggest that Bosnia and Herzegovina share similar value sets as some developed economies (Howard, 1998; Lamond, 2003).

As the respondents constitute a random, representative sample of managers and their organizations, these results suggest vague insight for Bosnia and Herzegovina's organizations. Employing competing values instrument for measuring organ- izational effectiveness, Bosnia and Herzegovina's organizations are now in a situation to detect the extent to which their value systems are consistent with competing values paradigm, identify the objects that disable them from operating according to organizations effectiveness models, and define the certain types of practices and policies consistent with dominant and emphasized values in organizations to produces better goals and fulfil expectations of their stakeholders.

One of the limitations of the presented study is that there can be cases that the measure of the intensity of the organizational effectiveness varies systematically according to the different managerial roles that respondents had at time when survey is conducted. Also, the fact has to be considered that the data are self-report from individual questionnaires. For example, some managers that are more familiar with internal process like human resource management and accounting are detecting internal values easily, while managers with job descriptions more similar to external focus like marketing or strategic management are more probably to detect first certain external values. Even though there is no detected existence of systematic variations of this type in presented results, its potential existence cannot be discarded and some further studies need to be aware of it.

Also, relatively small person-samples may pose limitations on inferences drawn based on the research. Only 150 respondents filled the questionnaire giving answer onto 16 statements, for instance, rules out the factor analysis. The sample size is big enough for conducting multidimensional scaling (Rodgers, 1991). Better understanding and more objective results of the strength of each value dimension in specific organization and domination of the certain organizational effectiveness model upon other models would be provided by interviews several managers per organization.sm 


\section{References}

Andreadis, N. (2009). Learning and organizational effectiveness: A systems perspective. Performance Improvement, 48 (1), 5-11. doi.org/10.1002/pfi.20043

Baer, M., \& Frese, M. (2003). Innovation is not enough: Climates for initiative and psychological safety, process innovations, and firm performance. Journal of Organizational Behavior: The International Journal of Industrial, Occupational and Organizational Psychology and Behavior, 24 (1), 45-68. doi.org/10.1002/job.179

Barnard, C. I. (1938). The Functions of the Executive. Cambridge, MA: Harvard University Press.

Buenger, V., Daft, R. L., Conlon, E. J., \& Austin, J. (1996). Competing values in organizations: Contextual influences and structural consequences. Organization Science, 7 (5), 557-576. doi.org/10.1287/orsc.7.5.557

Cameron, K. S., \& Freeman, S. J. (1991). Cultural Congruence, Strength, and Type: Relationships to Effectiveness. Research in Organizational Change and Development, 5, 23-58.

Chermack, T. J., Bodwell, W., \& Glick, M. (2010). Two strategies for leveraging teams towards organizational effectiveness: Scenario planning and organizational ambidexterity. Advances in Developing Human Resources, 12 (1), 137-156. doi.org/10.1177/ 1523422310365669

Chun, Y. H., \& Rainy, H. G. (2005). Goal ambiguity and organizational performance in U.S. Federal agencies. Journal of Public Administration Research and Theory, 15, 529-557. doi.org/10.1093/jopart/mui030

Ebben, J. J., \& Johnson, C. A. (2005). Efficiency, flexibility, or both? Evidence linking strategy to performance in small firms. Strategic Management Journal, 26, 12491259. doi.org/10.1002/smj.503

Fey, C. F., \& Denison, D. R. (2003). Organizational culture and effectiveness: Can American theory be applied in Russia? Organizational Science, 14 (6), 686-706. doi.org/10.1287/orsc.14.6.686.24868

Finklestein, S. (2003). Why smart executives fail. New York: Penguin Portfolio.

Hair, J. F., Anderson, R. E., Tatham, R. L., \& Black, W. C. (1998). Multivariate Data Analysis. New Jersey: Prentice-Hall International.

Hair, J. F., Hult, G. T. M., Ringle, C. M., \& Sarstedt, M. (2017b). A primer on partial least squares structural equation modeling (PLS-SEM) (2nd ed.). Thousand Oaks: Sage.

Hall, R. H. (1980). Effectiveness theory and organizational effectiveness. The journal of applied Behavioral science, 16 (4), 536-545. doi.org/10.1177/002188638001600408

Hart, S. L., \& Quinn, R. E. (1993). Roles executives play: CEOs, behavioral complexity, and firm performance. Human relations, 46 (5), 543-574. doi.org/10.1177/ 001872679304600501

Howard, L.W. (1998). Validating the competing values model as a representation of organizational cultures. International Journal of Organizational Analysis, 6 (3), 231-50. doi.org/10.1108/eb028886

Jamrog, J. J., \& Overholt, M. H. (2004). Measuring HR and organizational effectiveness. Employment Relations Today, 31 (2), 33-45. doi.org/10.1002/ert.20015

Kalliath, T. J., Bluedorn, A. C. \& Gillespie, D. F. (1999). A confirmatory factor analysis of the competing values instrument. Educational and Psychological
Measurement, 59 (1), 143-158.

doi.org/10.1177/0013164499591010

Key, D. B., Reed, R., \& Sclar, A. (2005). First-order economizing: organizational adaptation and elimination of waste in the U.S. pharmaceutical industry. Journal of Managerial Issues, 17 (4), 511-527. Retrieved from http://www.jstor.org/stable/40604518

Kruskal, J. B. (1964). Multidimensional scaling by optimizing goodness of fit to a nonmetric hypothesis.

Psychometrika, 29 (1), 1-27. doi.org/10.1007/BF02289565

Lamond, D. (2003). The value of Quinn's competing values model in an Australian context. Journal of Managerial Psychology, 18 (1), 46-59. doi.org/10.1108/02683940310459583

Lemieux-Charles, L., McGuire, W., Champagne, F., Barnsley, J., Cole, D., \& Sicotte, C. (2003). The use of multilevel performance indicators in managing performance in health care organizations. Management Decision, 41 (8), 760-770. doi.org/10.1108/ 00251740310496279

Morris, M., Schindehutte, M., \& Allen, J. (2005). The entrepreneur's business model: Toward a unified perspective. Journal of Business Research, 58 (6), 726735. doi.org/10.1016/j.jbusres.2003.11.001

Quinn, R. E. (1988). Beyond Rational Management: Mastering the Paradoxes and Competing Demands of High Performance. San Francisco, CA: Jossey Bass/Wiley.

Quinn, R. E., \& Rohrbaugh, J. (1983). A spatial model of effectiveness criteria: Towards a competing values approach to organizational analysis. Management science, 29 (3), 363-377. doi.org/10.1287/mnsc.29.3.363

Rodgers, J. L. (1991). Matrix and stimulus sample sizes in the weighted MDS model: Empirical metric recovery functions. Applied psychological measurement, 15 (1), 71-77. doi.org/10.1177/014662169101500107

Schneider, S., \& Spieth, P. (2013). Business model innovation: Towards an integrated future research agenda. International Journal of Innovation Management, 17 (01), 1340001. doi.org/10.1142/S136391961340001X

Sundaray, B. K. (2011). Employee engagement: A driver of organizational effectiveness. European Journal of Business and Management, 3 (8), 53-59.

Tushman, M. L., \& Romanelli, E. (1985). Organizational evolution: a metamorphosis model of convergence and reorientation. In L. L. Cummings \& B.M. Staw (Eds.), Research in Organizational Behavior, (Vol. 7, pp. 171222) Greenwich, CT: JAI Press.

Young, W., \& Tilley, F. (2006). Can businesses move beyond efficiency? The shift toward effectiveness and equity in the corporate sustainability debate. Business Strategy and the Environment, 15 (6), 402-415. doi.org/10.1002/bse.510

Yukl, G., \& Lepsinger, R. (2004). Flexible leadership: creating value by balancing multiple challenges and choices. San Francisco, CA: Jossey Bass/Wiley. 


\section{$\triangle$ Correspondence}

\section{Matea Zlatković}

University of Banja Luka, Faculty of Economics

Majke Jugovića 4, 78000 Banja Luka, Bosnia and Herzegovina

E-mail: matea.zlatkovic@ef.unibl.org 